\title{
Supplementary Information for On the Acid Sites of Phosphorous modified Zeosils
}

Gaurav Kumar", Limin Ren, ${ }^{\dagger, \delta}$ Yutong Pang ${ }^{\ddagger}$, Xinyu Li ${ }^{\ddagger}$, Han Chen, ${ }^{\beta}$ Jason Gulbinski, ${ }^{\beta}$ Paul J.

Dauenhauer, ${ }^{\ddagger}, \delta$ Michael Tsapatsis, ${ }^{\ddagger, \delta, \xi, g}$ Omar A. Abdelrahman, ${ }^{\beta, \delta, *}$

*Department of Chemical Engineering and Materials Science, University of Minnesota, 421 Washington Avenue SE, Minneapolis, Minnesota 55455, United States

${ }^{\beta}$ Department of Chemical Engineering, University of Massachusetts Amherst, 686 N. Pleasant Street, Amherst, MA 01003.

$\xi$ Department of Chemical and Biomolecular Engineering \& Institute for NanoBioTechnology, Johns Hopkins University, 3400 N. Charles Street, Baltimore, MD 21218.

g Johns Hopkins University, Applied Physics Laboratory, 11100 Johns Hopkins Road, Laurel, MD 20723

${ }^{\delta}$ Catalysis Center for Energy Innovation, University of Delaware, 150 Academy Street, Newark, Delaware 19716, United States

*Corresponding Author: abdel@umass.com

\section{Table of Contents}

S.1 Synthesis and characterization of P-zeosils ...............................................................................

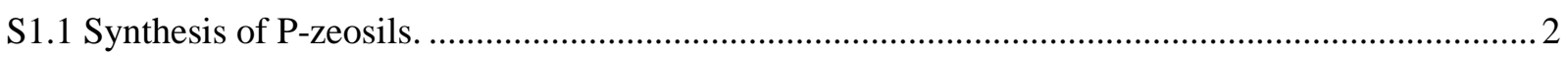

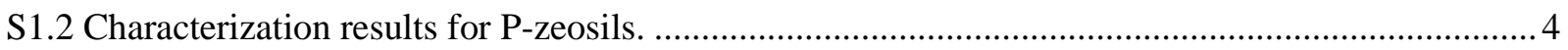

S.2 Optimized structures for all adsorption calculations .................................................................... 12

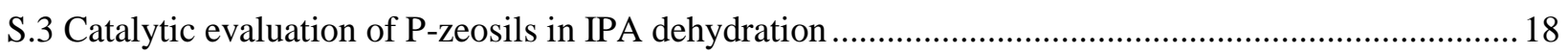

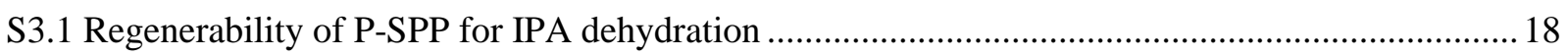

S3.2 Uni-/bimolecular selectivity during in-situ pyridine titration experiments .................................. 19

S3.3 Calculation of KIE for unimolecular IPA dehydration on P-SPP.............................................20

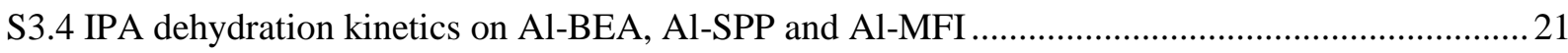

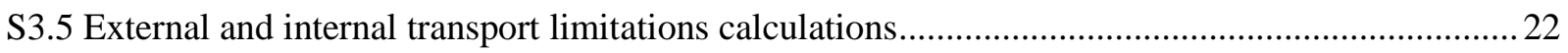

S3.6 Uni-, and bimolecular dehydration barriers as a function of pore-size for P-zeosils......................24 


\section{S.1 Synthesis and characterization of P-zeosils}

\section{S1.1 Synthesis of P-zeosils.}

All-silica zeolites used as supports for phosphoric acid were synthesized hydrothermally and the detailed procedures are listed below.

1- Si-SPP: The sample was synthesized with tetra(n-butyl)phosphonium hydroxide (TBPOH $40 \mathrm{wt} \%$, TCI America) as the structure-directing agent and tetraethyl orthosilicate (TEOS, 98\%, Sigma-Aldrich) as the

silica source, and detailed recipe can be found in Zhang et al. ${ }^{1}$ The products were collected by centrifuging and repeated washing with distilled water until $\mathrm{pH}<8$ and then dried at $70^{\circ} \mathrm{C}$ overnight. The as-synthesized sample was calcined at $550{ }^{\circ} \mathrm{C}$, and the removal of any remaining P-species from the decomposed SDA was removed by repeated washing with water. the calcined SPP was mixed with deionized water in a centrifuge tube and stirred in the oil bath $\left(70^{\circ} \mathrm{C}\right)$ for $30 \mathrm{~min}$, followed by centrifugation. This washing procedure was repeated 5 times, after which the sample was dried (at $70{ }^{\circ} \mathrm{C}$ overnight) and calcined at 500 ${ }^{\circ} \mathrm{C}$ for $4 \mathrm{~h}$ in a box furnace.

2- Si-BEA: Sample was prepared under fluoride media with tetraethylammonium hydroxide (TEAOH, 40 wt $\%$ in water, Sigma Aldrich) as the SDA, and tetraethyl orthosilicate (TEOS, 98\%, Sigma-Aldrich) as the silica source, and detailed recipe can be found in Camblor et al. ${ }^{2}$ After hydrothermal synthesis, the products were collected by centrifuging and repeated washing with distilled water until $\mathrm{pH}<8$ and then dried at 70 ${ }^{\circ} \mathrm{C}$ overnight and calcined at $550{ }^{\circ} \mathrm{C}$ for $4 \mathrm{~h}$ in a box furnace.

3- Si-MFI: Sample was hydrothermally synthesized in fluoride media with Tetrapropylammonium bromide as SDA and Cab-o-Sil M5 as the silica source, and the detailed recipe can be found in Chézeau et $\mathrm{al}^{3}$ After hydrothermal synthesis, the products were collected by centrifuging and repeated washing with distilled water until $\mathrm{pH}<8$ and then dried at $70^{\circ} \mathrm{C}$ overnight. The calcination for removal of surfactant was performed in a box furnace at $550^{\circ} \mathrm{C}$ for $10 \mathrm{~h}$.

4- Si-SBA-15: The sample was synthesized by modifying the recipe reported by Zhao et al. ${ }^{4}$ First, $20 \mathrm{ml}$ of $2 \mathrm{M} \mathrm{HCl}$ was mixed with $104 \mathrm{~g}$ deionized water and stirred for $10 \mathrm{~min}$ followed by adding $4 \mathrm{~g}$ of PEO-PPOPEO (P123, Sigma-Aldrich). The above mixture was stirred in a $40{ }^{\circ} \mathrm{C}$ oil bath for $30 \mathrm{~min}$ to dissolve the PEO-PPO-PEO. Then, 8.4g of tetraethyl orthosilicate (TEOS, Sigma-Aldrich) was added and stirred for $3 \mathrm{~h}$. The gel was then transferred to autoclaves and heated at $100^{\circ} \mathrm{C}$ for $24 \mathrm{~h}$. The products were collected 
by filtrating and repeated washing with deionized water and dried at $70{ }^{\circ} \mathrm{C}$ overnight. The calcination for removal of surfactant was performed in a box furnace at $560{ }^{\circ} \mathrm{C}$ for $10 \mathrm{~h}$ without flowing any gas.

5- Si-MCM-41: The sample was synthesized by the following method: $1.1 \mathrm{~g}$ of cetyltrimethylammonium bromide (CTAB) was mixed with $25 \mathrm{ml}$ of deionized water. Then $12 \mathrm{ml}$ of ammonia water (20-25\%, Aldrich) was added and stirred for $30 \mathrm{~min}$. Then $5 \mathrm{ml}$ of TEOS was added and stirred for $3 \mathrm{~h}$. The gel was then transferred to autoclaves and heated at $100^{\circ} \mathrm{C}$ for $24 \mathrm{~h}$. The products were collected by filtrating and repeated washing with distilled water and then dried at $70{ }^{\circ} \mathrm{C}$ overnight. The calcination for removal of surfactant was performed in a box furnace at $550{ }^{\circ} \mathrm{C}$ for $10 \mathrm{~h}$ without flowing any gas.

6- Si-Stöber: This sample was synthesized using the exact recipe as reported by Stöber et al. ${ }^{5}$ and is the same sample previously reported in Zhang et al. ${ }^{6}$

All P-containing zeosils except P-BEA were prepared using wet impregnation procedure as reported for preparation of P-BEA by Fan and co-workers. ${ }^{7}$ In this procedure, the $\mathrm{Si} / \mathrm{P}$ feeding was fixed at 25. Typically, first, $0.4 \mathrm{~g}$ of the mother all-silica sample, $18.2 \mu \mathrm{L}$ of $85 \mathrm{wt} \%$ phosphoric acid $\left(\mathrm{H}_{3} \mathrm{PO}_{4}\right.$, Sigma-Aldrich), and $3.33 \mathrm{~mL}$ of deionized water were mixed. Then, the impregnated sample was dried at $90{ }^{\circ} \mathrm{C}$ overnight, followed by calcination at $600^{\circ} \mathrm{C}$ for $25 \mathrm{~min}$. For the synthesis of P-BEA, the impregnation procedure was modified by using ethanol and water as co-solvents. First, a phosphoric acid solution was prepared by mixing $182 \mu \mathrm{l}$ of $\mathrm{H}_{3} \mathrm{PO}_{4}(85 \mathrm{wt} \%$, Sigma-Aldrich) and $8.325 \mathrm{~g}$ of deionized water. Then, $1 \mathrm{~g}$ of Si-BEA, $2.057 \mathrm{~g}$ of above phosphoric acid solution and $6 \mathrm{ml}$ of ethanol were mixed thoroughly. Then, the impregnated sample was dried at $90{ }^{\circ} \mathrm{C}$ overnight, followed by calcination at $600{ }^{\circ} \mathrm{C}$ for $25 \mathrm{~min}$. 
S1.2 Characterization results for P-zeosils.

\section{i) P-BEA}
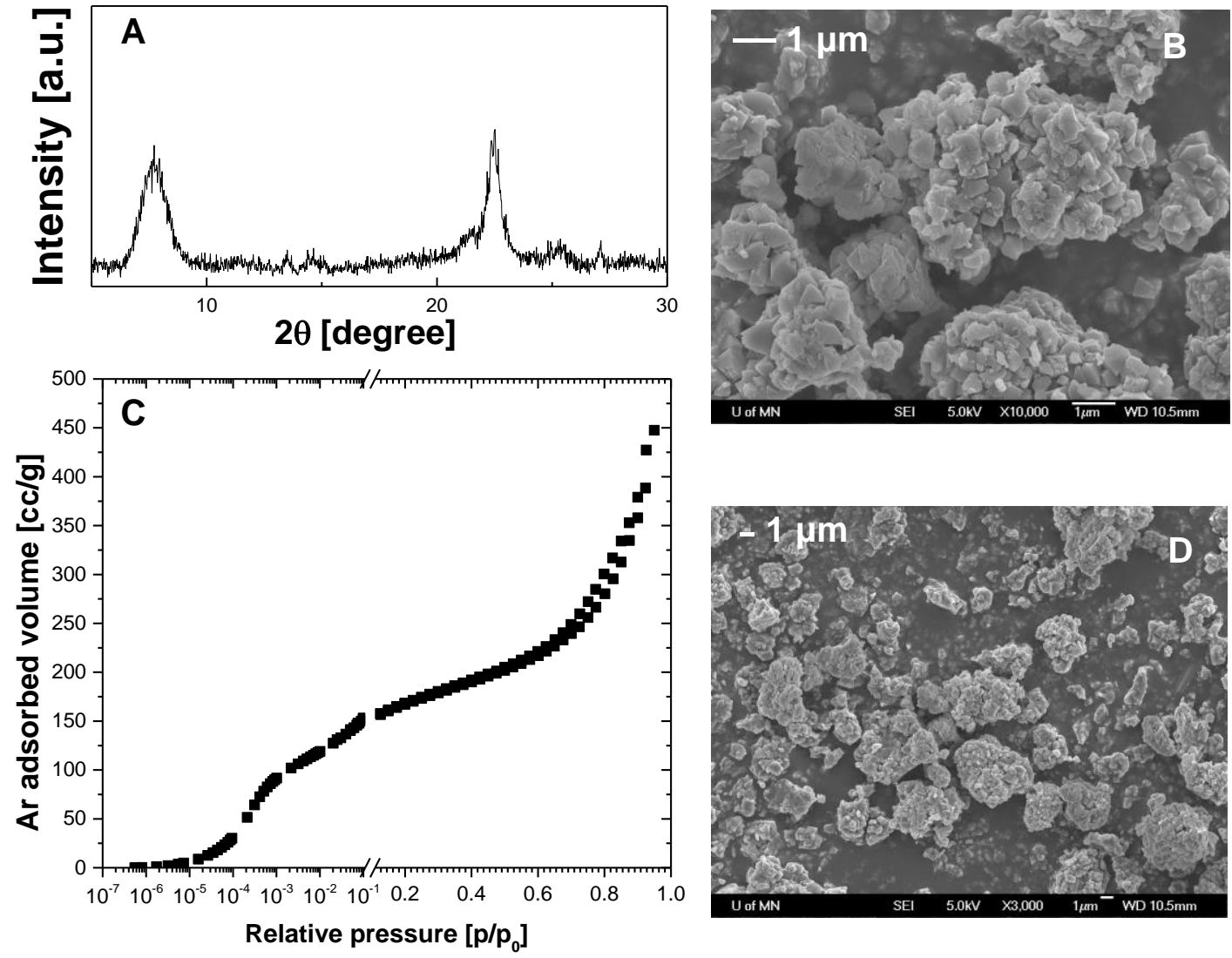

Figure S1. (A) PXRD patterns for P-BEA; (B \& D) SEM micrographs for P-BEA; (C) Ar adsorptiondesorption isotherms for P-BEA ( $\mathbf{\square})$. 
ii) P-SPP
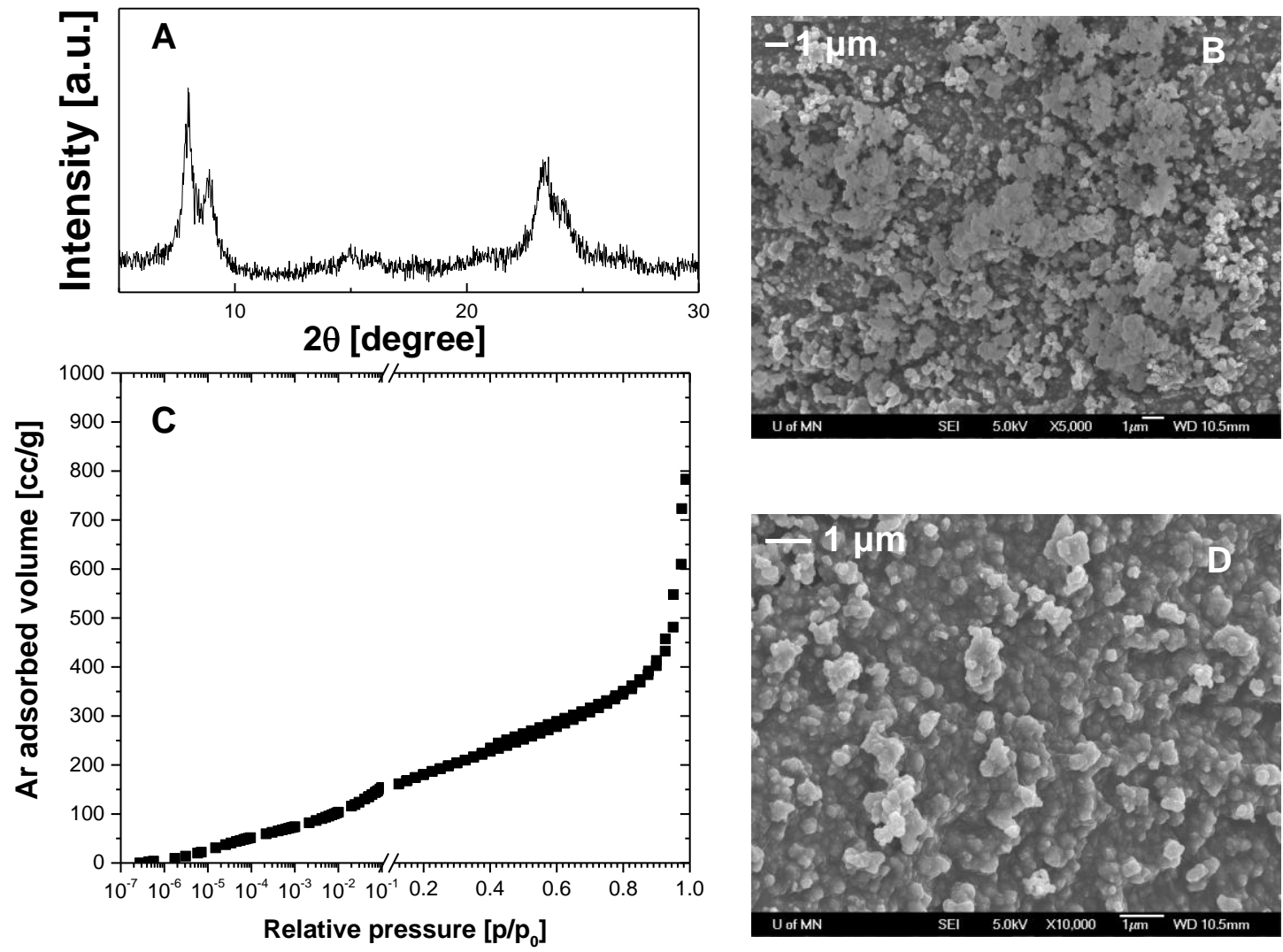

Figure S2. (A) PXRD patterns for P-SPP; (B \& D) SEM micrographs for P-SPP; (C) Ar adsorptiondesorption isotherms for P-SPP ( $\mathbf{\square})$. 
iii) P-SBA-15
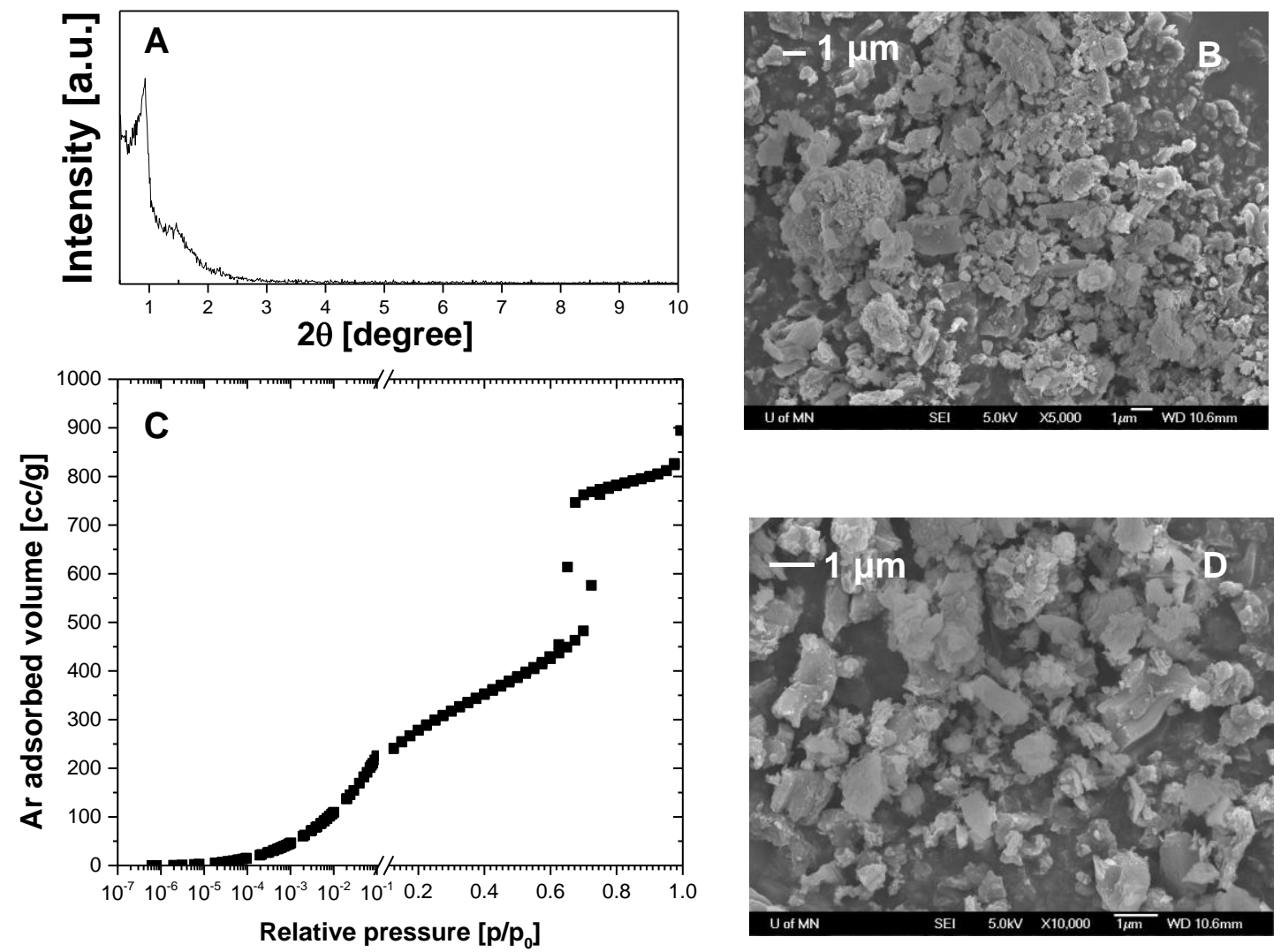

Figure S3. (A) PXRD patterns for P-SBA-15; (B \& D) SEM micrographs for P-SBA-15; (C) Ar adsorption-desorption isotherms for P-SBA-15 (匹). 
iv) P-MFI
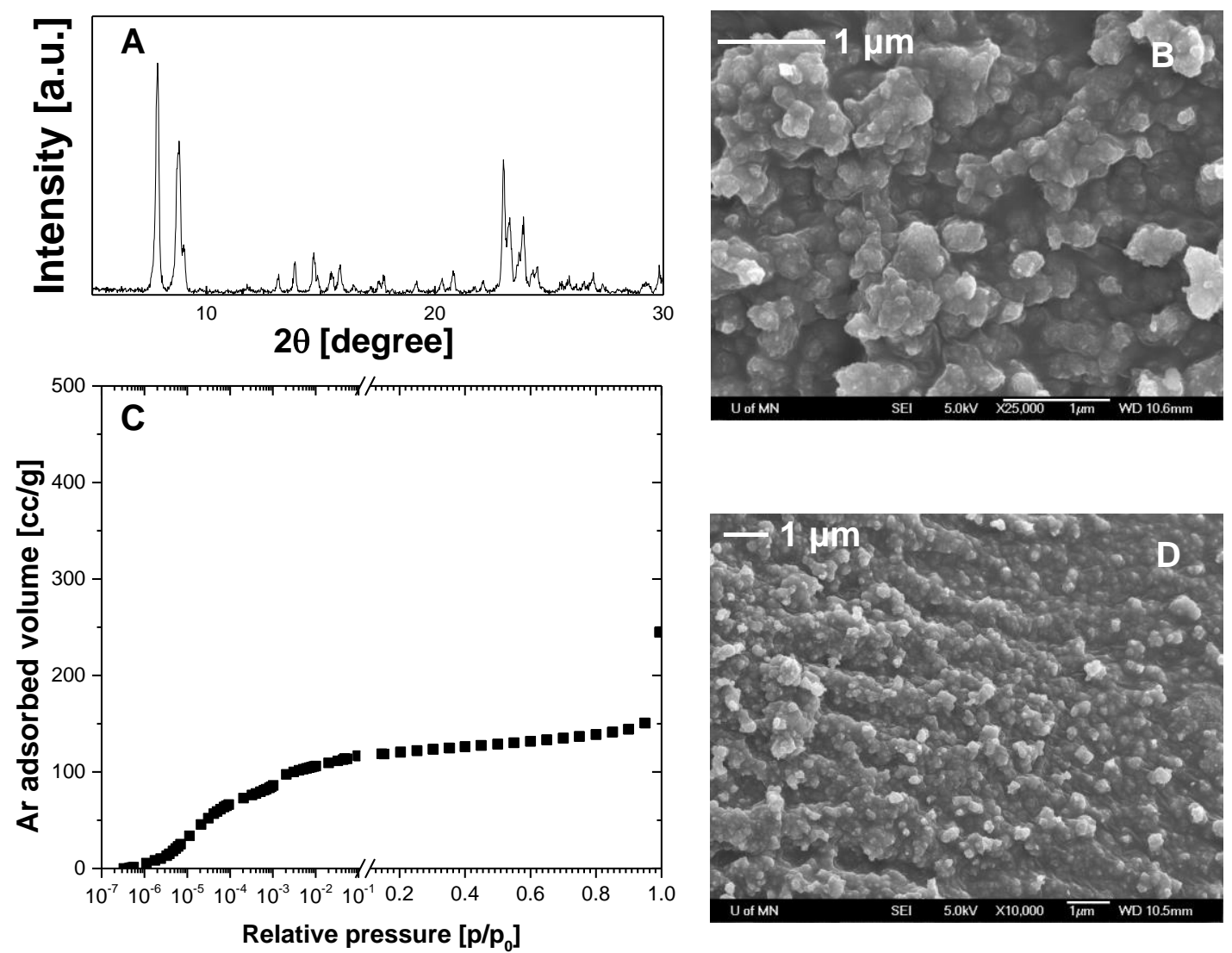

Figure S4. (A) PXRD patterns for P-MFI; (B \& D) SEM micrographs for P-MFI; (C) Ar adsorptiondesorption isotherms for P-MFI (๘). 
v) P-MCM-41
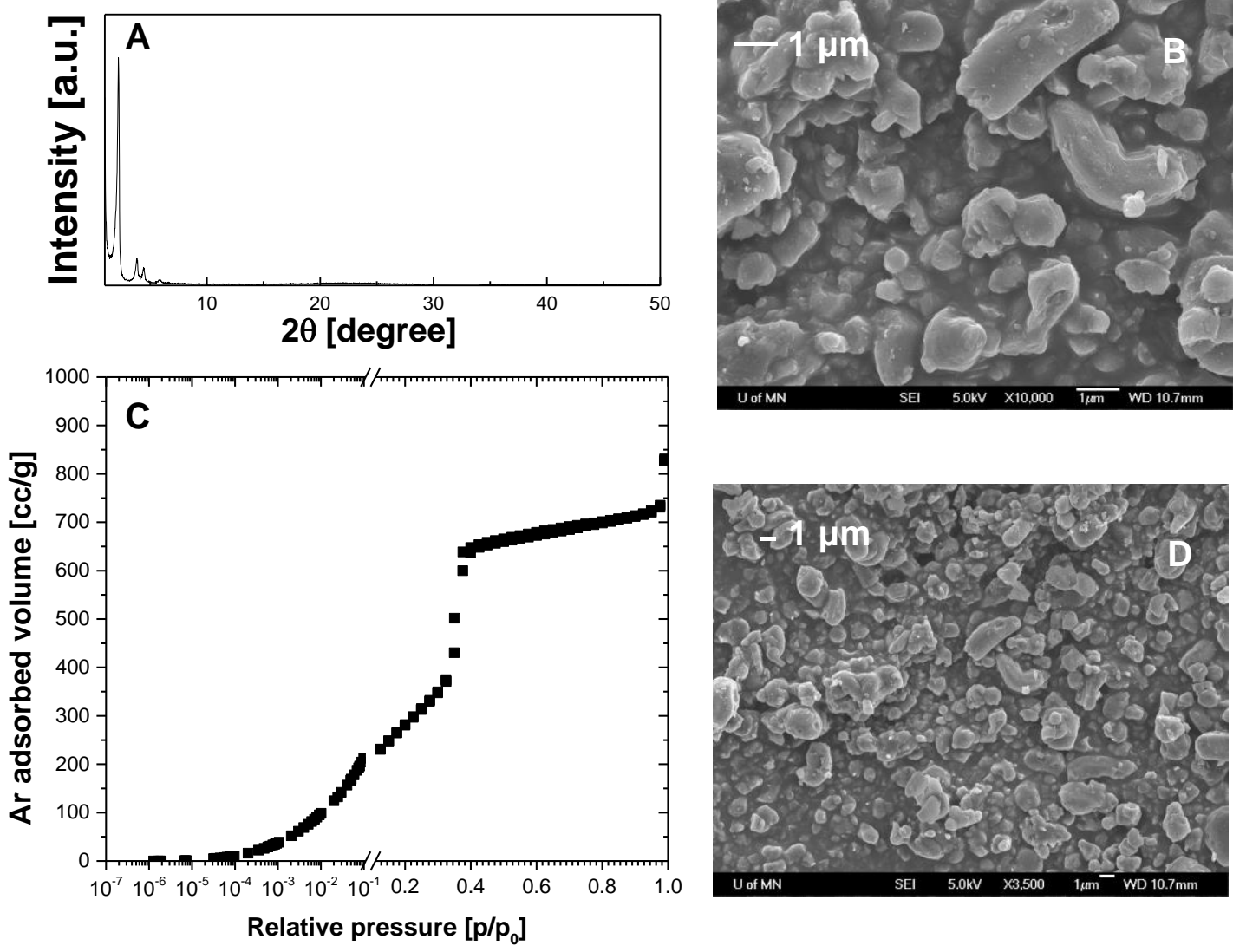

Figure S5. (A) PXRD patterns for P-MCM-41; (B \& D) SEM micrographs for P-MCM-41; (C) Ar adsorption-desorption isotherms for P-MCM-41 (ש). 
vi) P-Stöber
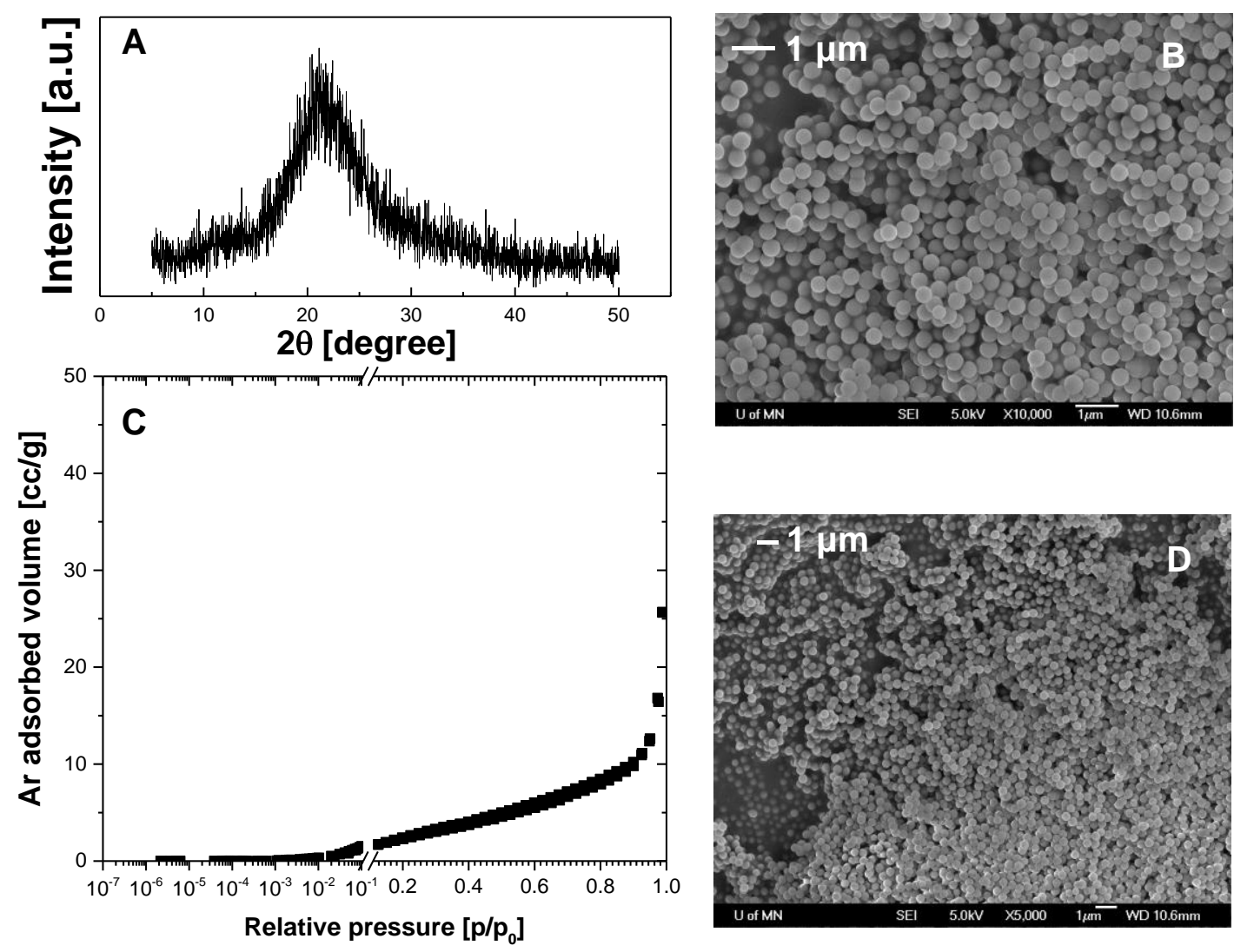

Figure S6. (A) PXRD patterns for P-Stöber ; (B \& D) SEM micrographs for P-Stöber ; (C) Ar adsorptiondesorption isotherms for P-Stöber ( $\square$ ). 
Table S1. Textural properties of all phosphorus-containing zeosils

\begin{tabular}{cccc}
\hline Catalyst & $\begin{array}{c}\text { BET area } \\
{\left[\mathbf{m}^{\mathbf{2}} \mathbf{g}^{-1}\right]}\end{array}$ & $\begin{array}{c}\text { Total pore } \\
\text { volume } \\
{\left[\mathbf{c m}^{\mathbf{3}} \mathbf{g}^{-1}\right]}\end{array}$ & $\begin{array}{c}\text { Micropore } \\
\text { volume }^{\mathbf{c}} \\
{\left[\mathbf{c m}^{\mathbf{3}} \mathbf{g}^{-1}\right]}\end{array}$ \\
\hline P-SPP & 544.2 & 0.61 & 0.32 \\
P-MFI & 326.5 & 0.20 & 0.12 \\
\hline P-BEA & 465.4 & 0.57 & 0.23 \\
\hline P-MCM-41 & 943.4 & 1.06 & 0.1 \\
\hline P-SBA-15 & 837.9 & 1.03 & 0.12 \\
\hline P-Stöber & 8.2 & 0.03 & 0.01
\end{tabular}

${ }^{a}$ Determined from Ar adsorption-desorption isotherms; ${ }^{b}$ Determined from Ar adsorption-desorption isotherms at $P / P_{0}=0.95$ for SPP, BEA, and MFI, and P/P $=0.99$ for SBA-15, Stöber, and MCM-41; ${ }^{c}$ Determined using t-plot method from Ar adsorption-desorption isotherms 
Table S2. Textural properties of aluminosilicates used in this study

\begin{tabular}{|c|c|c|c|c|}
\hline Catalyst & $\begin{array}{l}\text { Reference \# in } \\
\text { manuscript }\end{array}$ & $\begin{array}{l}\text { BET Surface area } \\
\qquad\left(m^{2} / g\right)^{a}\end{array}$ & $\begin{array}{l}\text { Total pore volume } \\
\qquad\left(\mathrm{cm}^{3} / \mathrm{g}\right)^{\mathbf{b}}\end{array}$ & $\begin{array}{c}\text { Micropore } \\
\text { volume }\left(\mathrm{cm}^{3} / \mathrm{g}\right)^{\mathrm{c}}\end{array}$ \\
\hline $\begin{array}{c}\text { Al-MFI } \\
(\mathrm{Si} / \mathrm{Al} 40)\end{array}$ & 5 & 405 & 0.26 & 0.13 \\
\hline $\begin{array}{c}\text { Al-SPP } \\
(\mathrm{Si} / \mathrm{Al} 62)\end{array}$ & 25 & 621 & 0.61 & 0.26 \\
\hline $\begin{array}{c}\text { Al-BEA } \\
(\mathrm{Si} / \mathrm{Al} 12.5)\end{array}$ & 5 & 439 & 0.29 & 0.15 \\
\hline
\end{tabular}




\section{S.2 Optimized structures for all adsorption calculations}
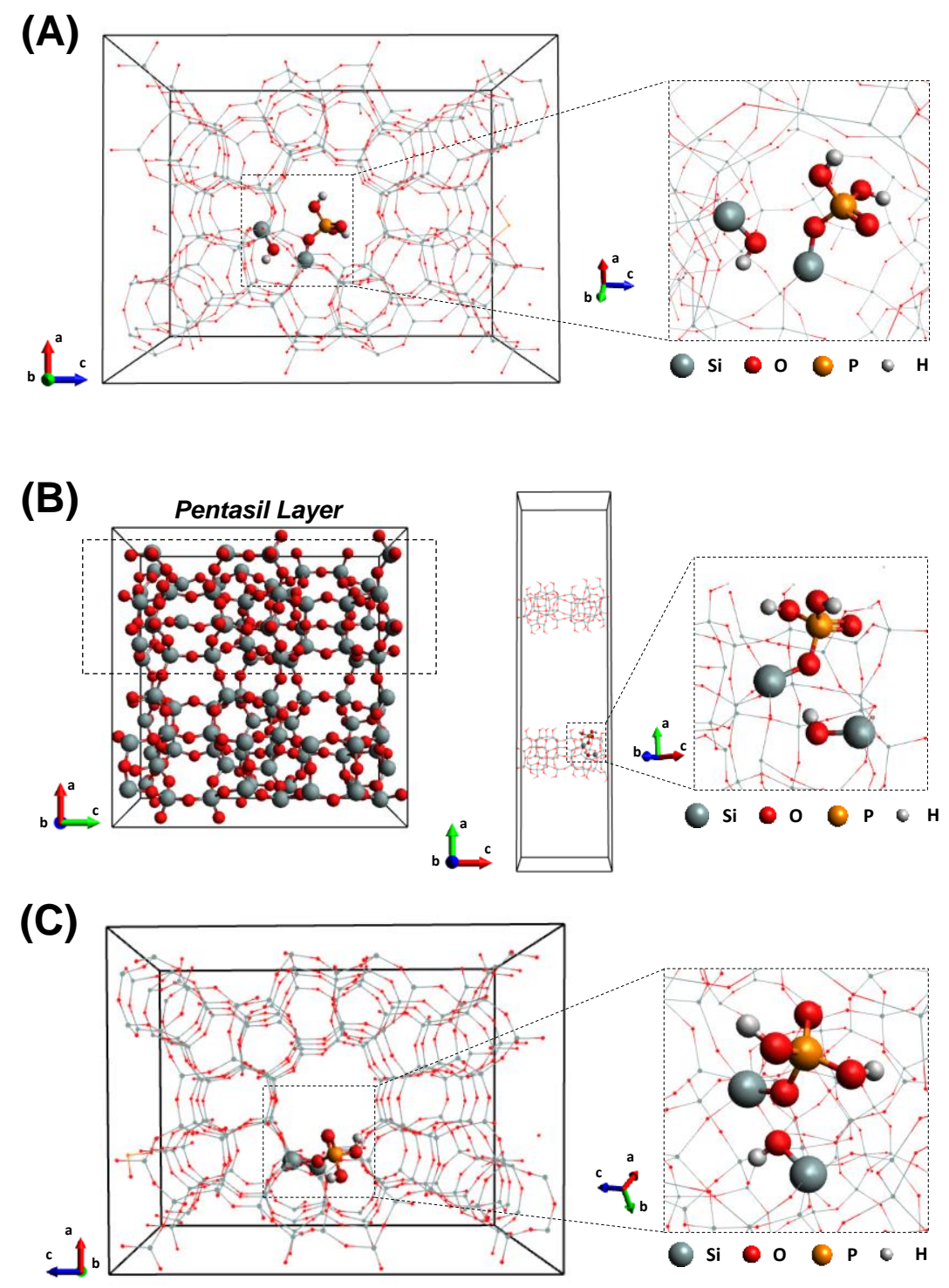

Figure S7. The optimized structures of (A) an internal P-active site and (B) an external P-active site on T2site in a P-MFI framework are presented. The structure containing the internal P-active site was optimized in a $1 \times 1 \times 1$-unit cell but shown in a $1 \times 1 \times 2$ supercell for better visualization of the site and adsorption interactions. (C) Optimized structure of an internal P-site on T-12 position. Silicon, oxygen, phosphorus, and hydrogen atoms are represented by grey, red, orange, and white solid balls respectively. 


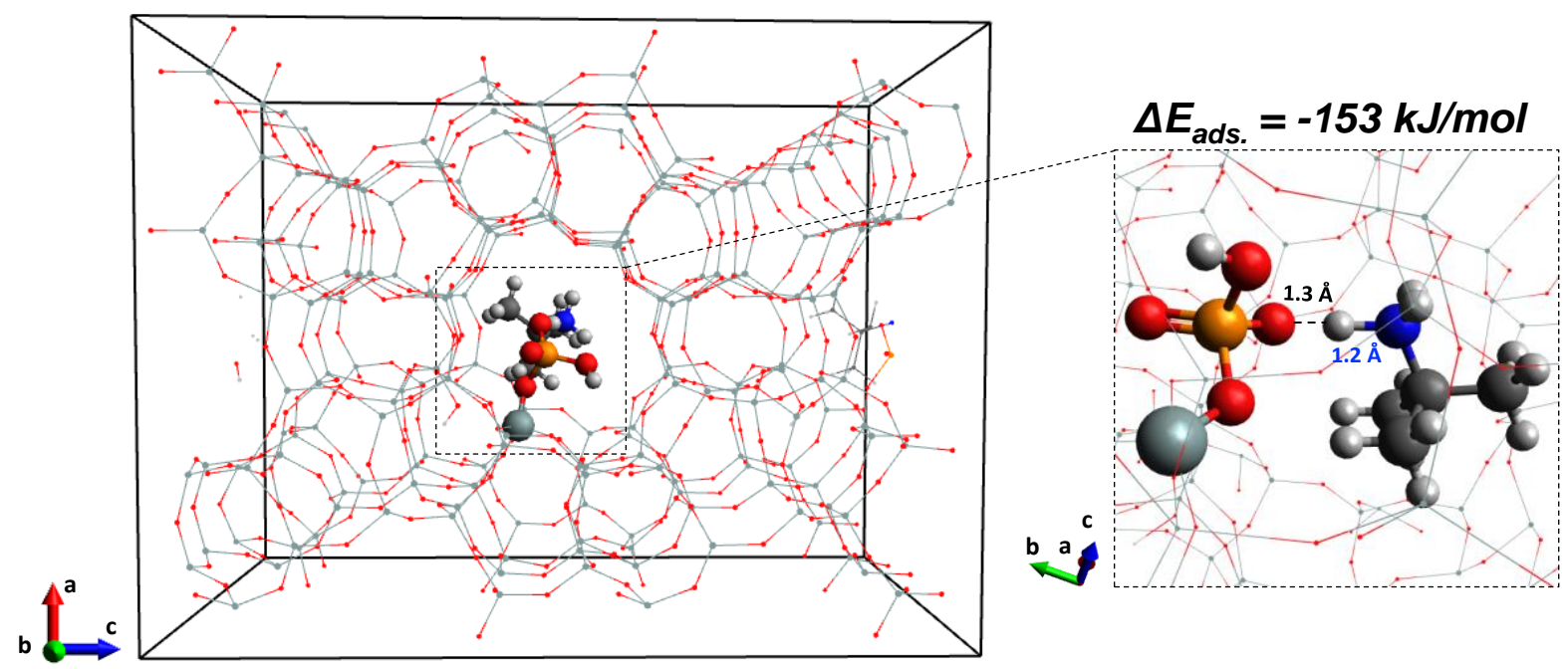

Figure S8. The optimized structures of tBA on an internal P-active site. The N-H atomic distances between the nitrogen of adsorbate and the proton of P-active site are shown in blue and the $\mathrm{O}-\mathrm{H}$ distances between the oxygen and hydrogen of the P-active site are shown in black. 

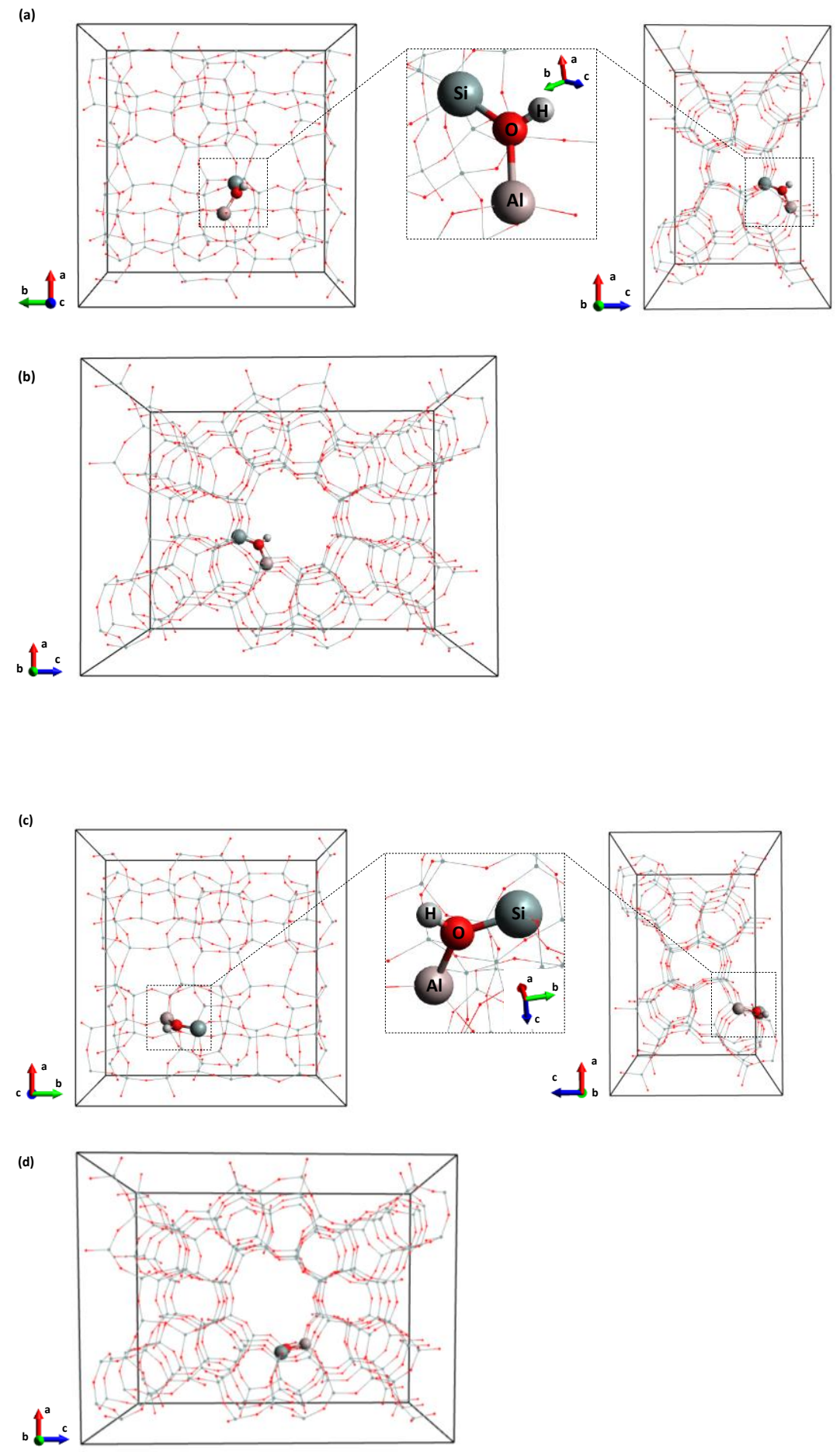

Figure S9. Optimized structure of an Al-MFI framework containing a BAS on the T2 position is shown in (a) a $1 \times 1 \times 1$-unit cell and (b) a $1 \times 1 \times 2$ supercell and a BAS on the T12 position is shown in (c) a $1 \times$ $1 \times 1$-unit cell and (d) a $1 \times 1 \times 2$ supercell. The supercell was constructed for more clear visualization of 
the internal sites and adsorption on internal sites. Silicon, aluminum, oxygen, and hydrogen atoms are represented by grey, pink, red, and white solid balls, respectively. 
(a)
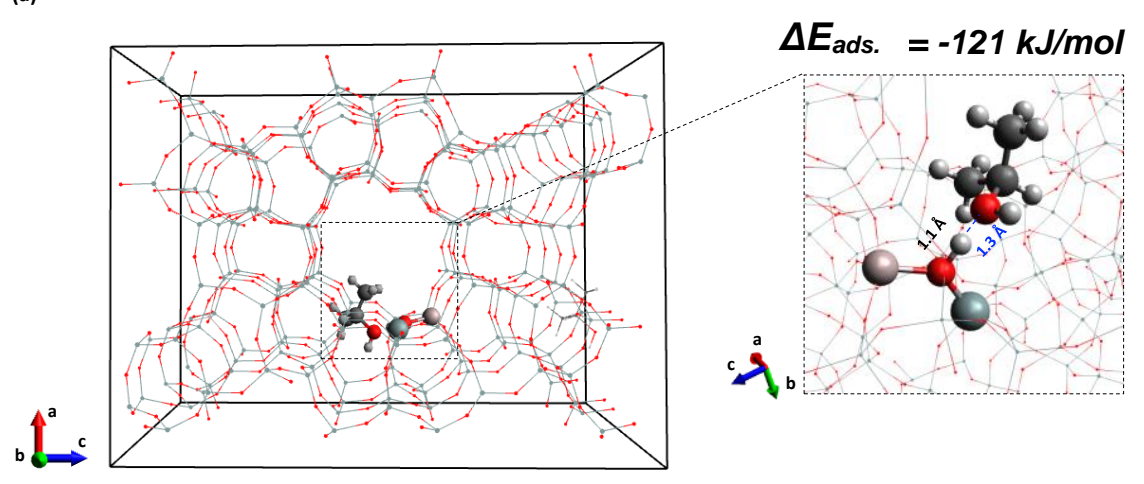

(b)
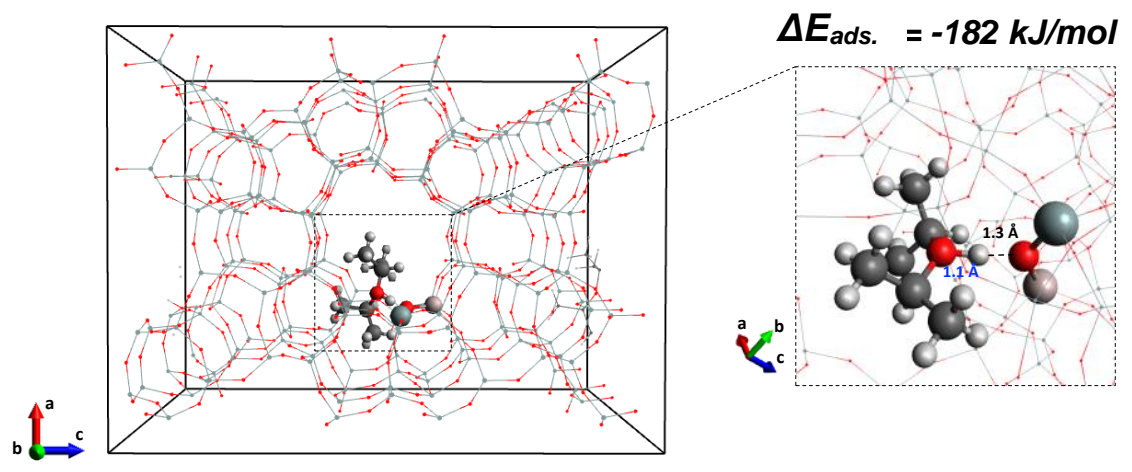

(c)

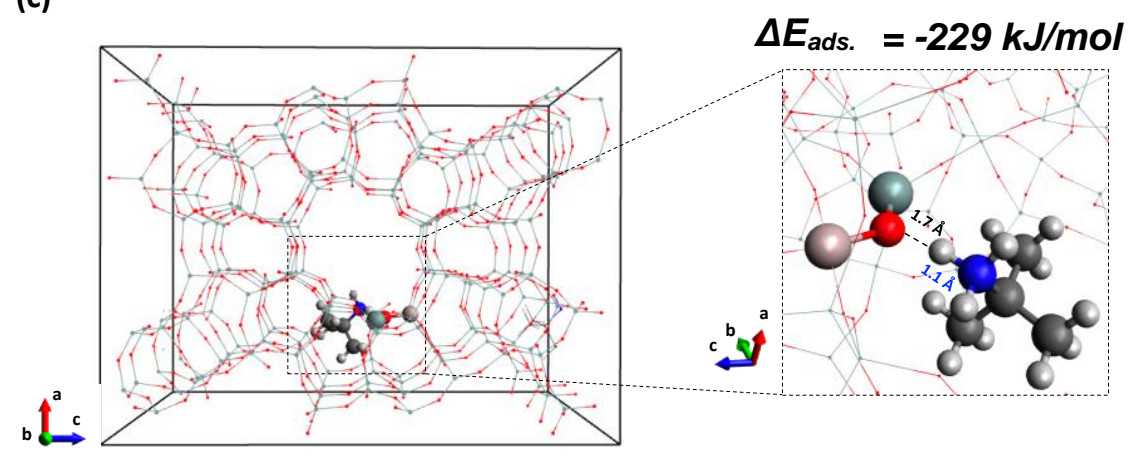

(d)

$$
\Delta E_{a d s^{*}}=-188 \mathrm{~kJ} \mathrm{~mol}^{-1}
$$

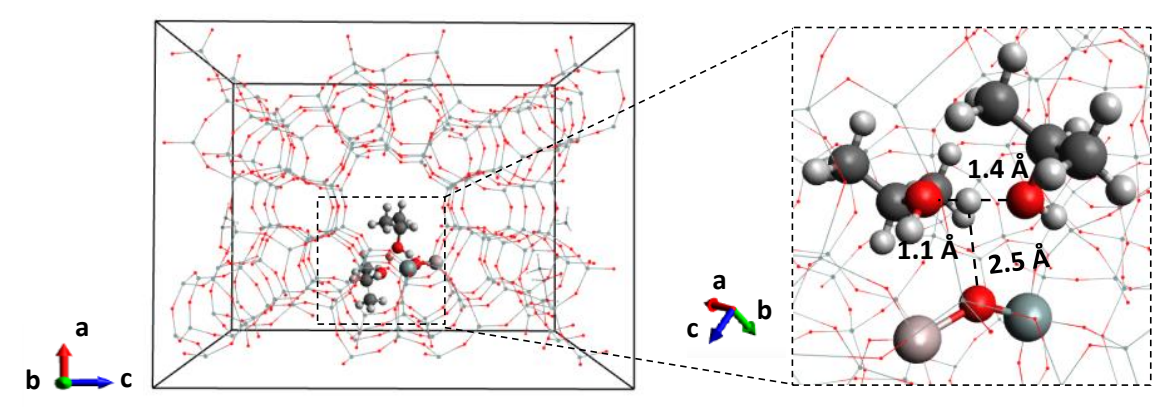


Figure S10. The optimized structures of (a) IPA, (b) DIPE, (c) tert-butylamine, and d) IPA dimer adsorbed on an internal BAS at the T12 in an Al-MFI framework are shown. The O-H or N-H distances between the oxygen/nitrogen and hydrogen of the BAS site are shown in black. 
S.3 Catalytic evaluation of P-zeosils in IPA dehydration

S3.1 Regenerability of P-SPP for IPA dehydration

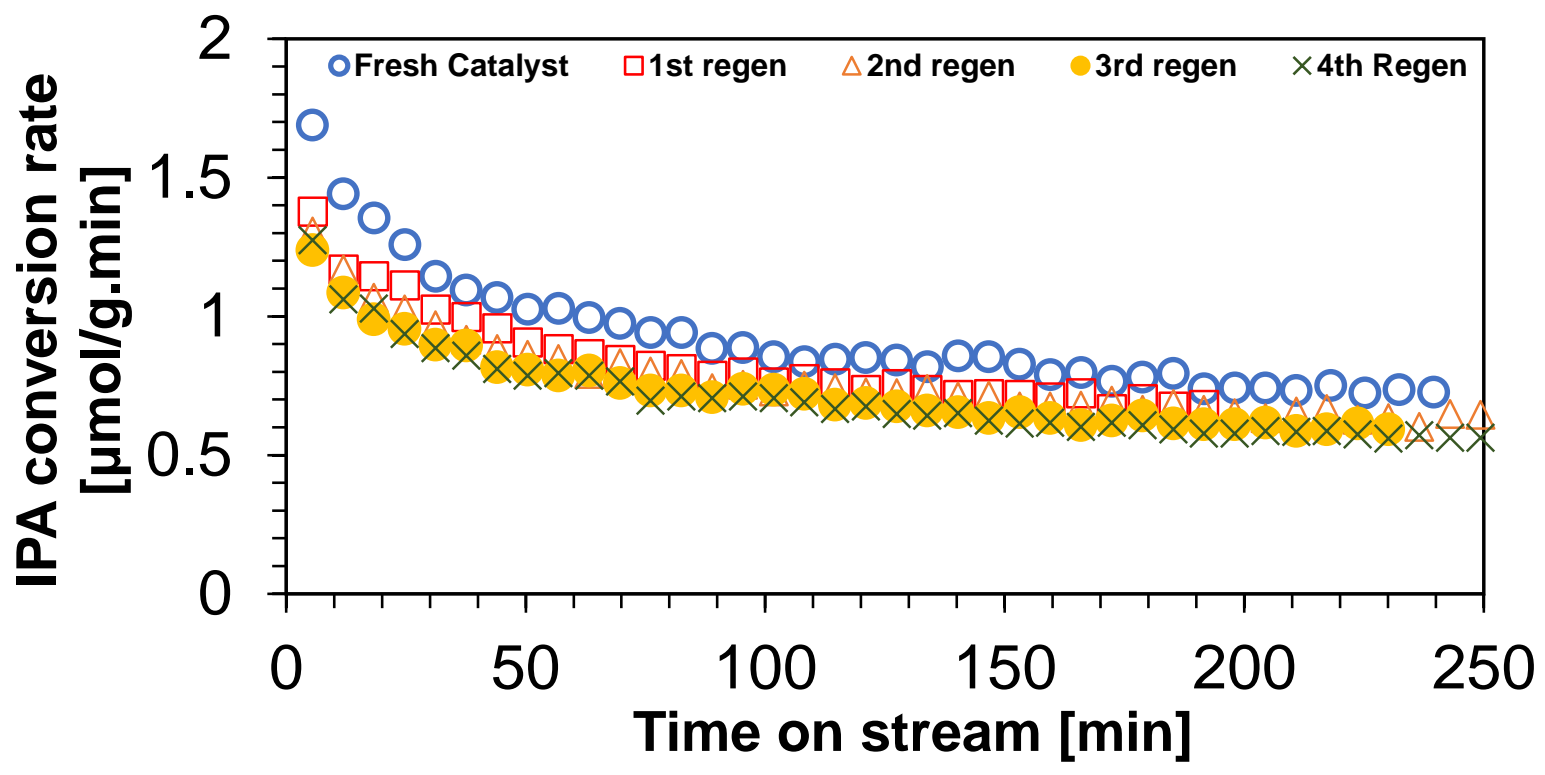

Figure S11. Time-on-stream data for IPA conversion rates measured on P-SPP after cycles of regeneration by in-situ calcination at $823 \mathrm{~K}$. (Reaction conditions $\mathrm{p}_{\mathrm{IPA}}=30$ torr; $\mathrm{T}=403 \mathrm{~K}$; WHSV $2.69 \mathrm{~g} \mathrm{IPA} / \mathrm{g}$ cat./h; Diluent (He) flowrate $25 \mathrm{sccm})$. 


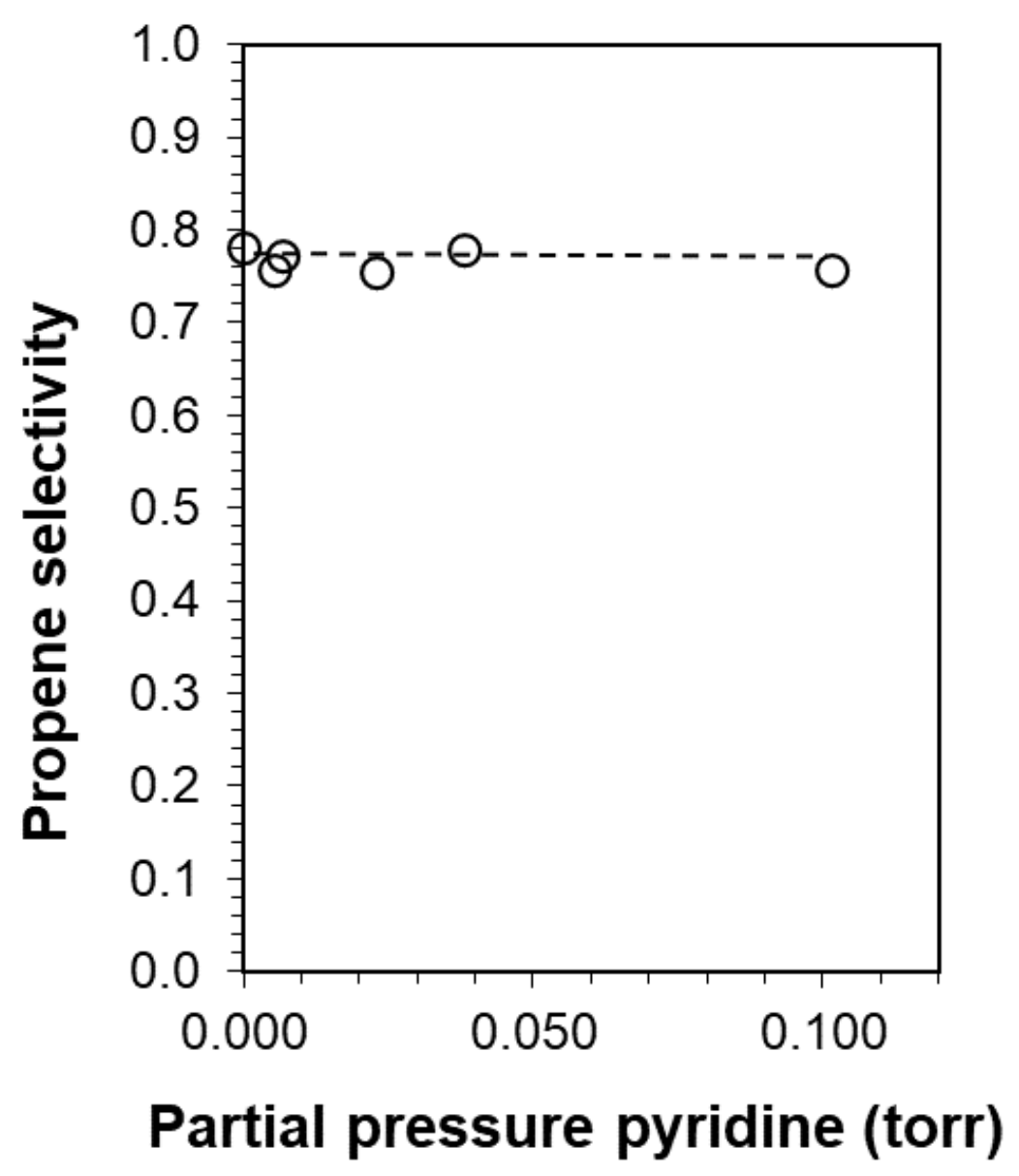

Figure S12. Fractional propene selectivity as a function of pyridine partial pressure during in-situ pyridine titration experiments on P-SPP. The reported values correspond to the selectivities after pyridine saturation. Reaction conditions are the same as Figure 9A in the main text. The dashed line is the linear regression to the experimental data. 


\section{S3.3 Calculation of KIE for unimolecular IPA dehydration on P-SPP}

Investigation of isotopic labeling on rates are used to calculate kinetic isotope effects (KIE), defined as Equation S1:

$\mathrm{KIE}=\frac{k_{H}}{k_{D}}$

where $\mathrm{k}_{\mathrm{H}}$ is the rate constant for the reaction with no deuterium atoms in the reactants, and $\mathrm{k}_{\mathrm{D}}$ is the rate constant for reaction with deuterium atoms in the reactants. For a rate-limiting step involving the cleavage of C-H bonds, the KIE value can be estimated by the following equation ${ }^{8}$

$\mathrm{KIE}=\frac{k_{H}}{k_{D}}=\exp \left(\frac{0.1865}{T} v_{H}\right)$

where $\mathrm{T}$ is the absolute temperature and $v_{\mathrm{H}}$ is the vibrational frequency of the $\mathrm{C}-\mathrm{H}$ in the units of $\mathrm{cm}^{-1}$. The C-H bond stretching frequency is $\sim 2985 \mathrm{~cm}^{-1},{ }^{8}$ implying the estimated KIE value involving the cleavage of a C-H bond is 3.98 at $403 \mathrm{~K}$.

For a rate-limiting step involving the re-hybridization of $\alpha$ carbon from $\mathrm{sp}^{3}$ to $\mathrm{sp}^{2}$ hybridization in the transition state, the KIE value can be estimated by the following equation ${ }^{8}$

$\mathrm{KIE}=\frac{k_{2, H}}{k_{2, D}}=\exp \left(-\frac{0.1865}{T}\left(v_{C-H}^{\#}-v_{C-H}^{R}\right)\right)$

where $v^{\#}$ is the vibrational frequncy of an $\mathrm{C}_{\alpha}-\mathrm{H}$ bond of the transition state and the $v^{\mathrm{R}}$ is the vibrational frequncy of the corresponding $\mathrm{C}_{\alpha}-\mathrm{H}$ bond of the reactant molecules. For a transition state with $\mathrm{sp}^{3}$ hybridization on the $\alpha$ carbon and a reactant with $\mathrm{sp}^{2}$ hybridization on $\alpha$ carbon, the $v^{\#}$ is $\sim 800 \mathrm{~cm}^{-1}$ and the $v^{\mathrm{R}}$ is $\sim 1350 \mathrm{~cm}^{-1,},{ }^{8}$ so the estimated KIE value is calculated to be 1.3 at $403 \mathrm{~K}$. 


\section{S3.4 IPA dehydration kinetics on Al-BEA, Al-SPP and Al-MFI}

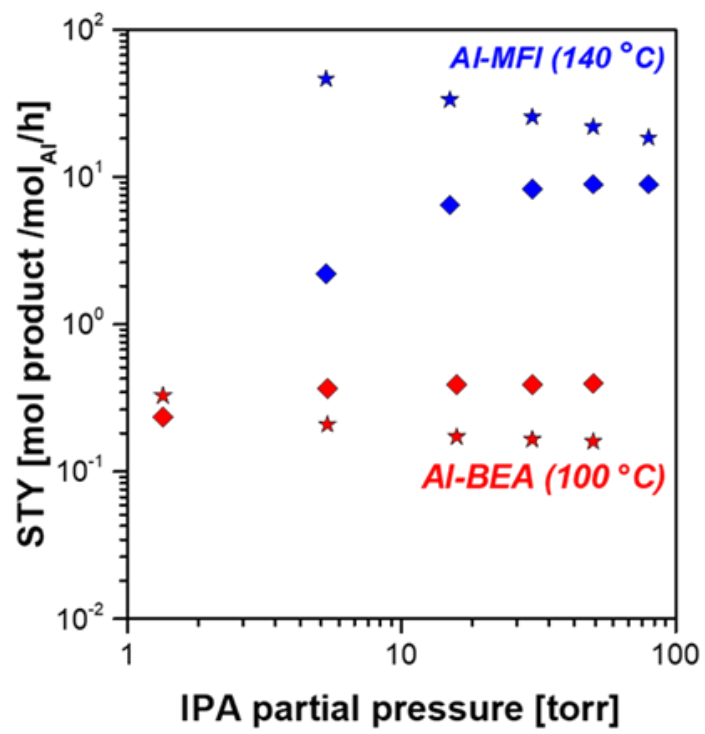

Figure S13. Propylene $(\star)$ and di-isopropyl ether $(\star)$ synthesis rates as a function of IPA partial pressures measured on Al-BEA ( $\mathrm{Si} / \mathrm{Al}$ 12.5) (red) and Al-MFI ( $\mathrm{Si} / \mathrm{Al}$ 40) (blue) (Reaction conditions: WHSV=2.5 g reactant/g cat./h; Carrier gas $(\mathrm{He})$ flowrate $=100 \mathrm{sccm}$; Conversions below $2.0 \%$ ).

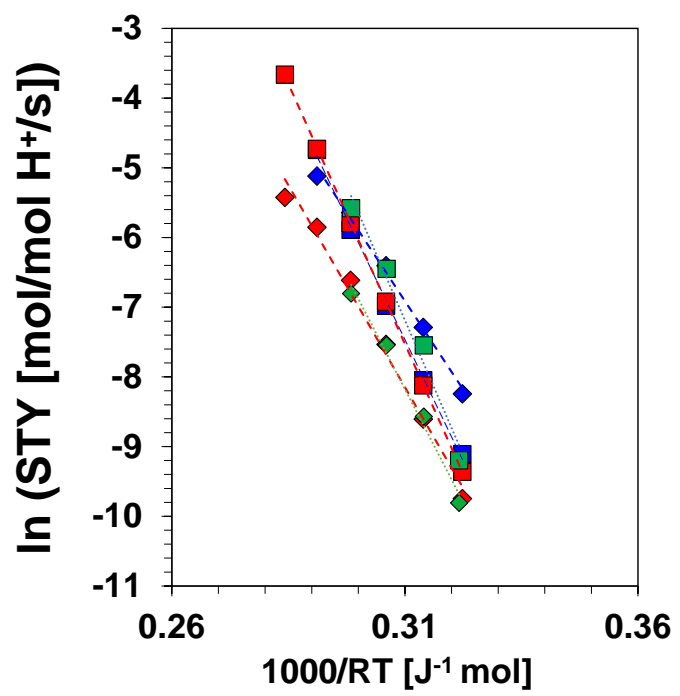

Figure S14. Arrhenius plots of propylene $(\square)$ and di-isopropyl ether $(\diamond)$ synthesis rates measured on AlBEA (Si/Al 12.5) (blue), Al-SPP (Si/Al 62) (green) Al-MFI (Si/Al 40) (red) (Reaction conditions: $\mathrm{p}_{\mathrm{IPA}}=$ 30 torr, WHSV=28.6-604 g reactant/g cat./h; Carrier gas $(\mathrm{He})$ flowrate $=100 \mathrm{sccm}$; Conversions below $8.5 \%)$ 


\section{S3.5 External and internal transport limitations calculations}

Mears' criterion was used to estimate the existence of any external mass transfer calculations when measuring reaction rates. This was done for the catalyst exhibiting the highest mass-normalized rates (PMFI) at the highest temperature (443 K). It can be safely assumed that the less active catalysts (per mass basis) will not be external transport-limited provided this limiting case does not show these limitations at identical reaction conditions. External mass transfer limitations can be neglected if the Eq. S4 inequality is satisfied

$$
\frac{r_{o b s} \rho_{b} R n}{k_{c} C_{b}}<0.15
$$

Where $r_{\text {obs }}$ is the observed rate of reaction in mol kgcat ${ }^{-1} \mathrm{~s}^{-1}, \rho_{\mathrm{b}}$ is the catalyst bed density in $\mathrm{kg} \mathrm{m}^{-3}\left(\rho_{\mathrm{b}}=(1\right.$ $\phi) \rho_{\mathrm{c}}$ where $\phi$ is the bed void fraction and $\rho_{\mathrm{c}}$ is the density of the catalyst, reported as $\left.1000 \mathrm{~kg} \mathrm{~m}^{-3}\right), \mathrm{R}$ is the catalyst aggregate size in $\mathrm{m}, \mathrm{n}$ is the reactant reaction rate order, $\mathrm{k}_{\mathrm{c}}$ is the external mass transfer coefficient in $\mathrm{m} \mathrm{s}^{-1}$, and $\mathrm{C}_{\mathrm{b}}$ is the reactant bulk concentration in $\mathrm{mol} \mathrm{m}^{-3}$.

Table S3. Tabulation of parameters for the calculation of Mears' Criteria for IPA dehydration on P-MFI (Si/P 36) at $443 \mathrm{~K}$

\begin{tabular}{|c|c|}
\hline Parameter & Value \\
\hline $\mathrm{r}_{\mathrm{obs}}\left(\mathrm{mol} \mathrm{kgcat}^{-1} \mathrm{~s}^{-1}\right)$ & $6.85 \times 10^{-3}$ \\
\hline$\rho_{\mathrm{b}}\left(\mathrm{kg}_{\text {cat }} \mathrm{m}^{-3}\right)$ & $700\left(\rho_{\mathrm{c}}=1000\right.$, assumed $\left.\phi=0.3\right)$ \\
\hline $\mathrm{R}(\mathrm{m})$ & $1.78 \times 10^{-4}($ average mesh size of $106-250 \mu \mathrm{m})$ \\
\hline $\mathrm{k}_{\mathrm{c}}\left(\mathrm{m} \mathrm{s}^{-1}\right)^{\mathrm{a}}$ & 0.055 \\
\hline $\mathrm{C}_{\mathrm{b}}\left(\mathrm{mol} \mathrm{m}^{-3}\right)$ & 1.09 (30 torr IPA; total pressure 787.6 torr) \\
\hline $\mathrm{n}$ & 0 \\
\hline
\end{tabular}

${ }^{\mathrm{a}}$ Estimated assuming Sh (Sherwood Number) $=\mathrm{k}_{\mathrm{c}}(2 \mathrm{R}) / \mathrm{D}=2+0.6 \operatorname{Re}^{1 / 2} \mathrm{Sc}^{1 / 3} ; \operatorname{Re}($ Reynolds Number) $=\rho \mathrm{U}(2 \mathrm{R}) / \mu$ and Sc $\left(\right.$ Schmidt number) $=\mu / \rho \mathrm{D}$, where $\rho=$ bulk gas density (Assumed to be $\mathrm{He}$ at $443 \mathrm{~K}, \rho=0.13 \mathrm{~kg} \mathrm{~m}^{-3}$ ), $\mathrm{U}=$ superficial velocity (total volumetric flow rate $\left(0.42 \mathrm{~cm}^{3} \mathrm{~s}^{-1}\right)$; tube diameter $(2 \mathrm{R})=4 \times 10^{-3} \mathrm{~m}$ : $\left.\mathrm{U}=3.34 \times 10^{-2} \mathrm{~m} \mathrm{~s}^{-1}\right)$, and $\mu=$ gas viscosity (estimated as He viscosity at $443 \mathrm{~K}=2.6 \times 10^{-5} \mathrm{~Pa} \mathrm{~s}$ ). $\mathrm{D}$ is gas phase diffusivity, estimated using Chapman-Enskog theory of diffusivity for IPA in He at $443 \mathrm{~K}=9.52 \times 10^{-5} \mathrm{~m}^{2} \mathrm{~s}^{-1}$ ).

The Mears criterion parameter show the reported rates are not corrupted by external mass transfer limitations.

Internal mass transfer limitations were evaluated by using the Weisz-Prater criterion (Eq S.5) for the highest temperature on all the six catalysts.

$$
C_{W P}=\eta \phi^{2}=\frac{r_{o b s} \rho_{c} R^{2}}{D_{e} C_{A s}}
$$


where $\eta$ is the dimensionless effectiveness factor, $\phi^{2}$ is the dimensionless Thiele modulus, $D_{e}$ is the effective diffusivity in $\mathrm{m}^{2} \mathrm{~s}^{-1}\left(\mathrm{D}_{\mathrm{e}}\right) \rho_{\mathrm{c}}$ is the particle density of the catalyst (assumed $1000 \mathrm{~kg} / \mathrm{m}^{3}$ ) and $\mathrm{C}_{\mathrm{As}}$ is the reactant surface concentration in mol m $\mathrm{m}^{-3}$ (Mears' criterion showed that there were no external mass transfer limitations, and hence we assume $\mathrm{C}_{\mathrm{As}}=\mathrm{C}_{\mathrm{b}}$ ). The upper limit of $\eta \varphi^{2}$ to safely assume that reaction is not diffusion limited is typically taken to be $\sim 0.3$.

Table S4. Tabulation of parameters for the calculation of the Weisz-Prater Criterion for IPA dehydration on P-MFI (Si/P 36) at $443 \mathrm{~K}$

\begin{tabular}{|c|c|}
\hline Parameter & Value \\
\hline $\mathrm{r}_{\mathrm{obs}}\left(\mathrm{mol} \mathrm{kgcat}^{-1} \mathrm{~s}^{-1}\right)$ & $6.85 \times 10^{-3}$ \\
\hline$\rho_{\mathrm{c}}\left(\mathrm{kg}_{\mathrm{cat}} \mathrm{m}^{-3}\right)$ & 1000 \\
\hline $\mathrm{R}(\mathrm{m})$ & $\begin{array}{c}1 \times 10^{-6} \text { (highest observed from SEM images in } \\
\text { Figure } \mathbf{S 4} \text { ) }\end{array}$ \\
\hline $\mathrm{C}_{\mathrm{As}}\left(\mathrm{mol} \mathrm{m}^{-3}\right)$ & 1.09 (30 torr IPA; total pressure 787.6 torr) \\
\hline$D_{e}\left(m^{2} s^{-1}\right)^{a}$ & $5.98 \times 10^{-10}($ assumed $\varepsilon=0.35, \delta=0.8, \tau=6)$ \\
\hline
\end{tabular}

${ }^{\mathrm{a}}$ Calculated by the extending the Arrhenius plots reported for IPA diffusivity in the temperature range $285-343 \mathrm{~K}$ on silicalite-1 in Lin et al. ${ }^{9}$ to $443 \mathrm{~K}$.

The Weisz-Prater criterion parameter show the reported rates are not corrupted by internal mass transfer limitations. 
S3.6 Uni-, and bimolecular dehydration barriers as a function of pore-size for P-zeosils

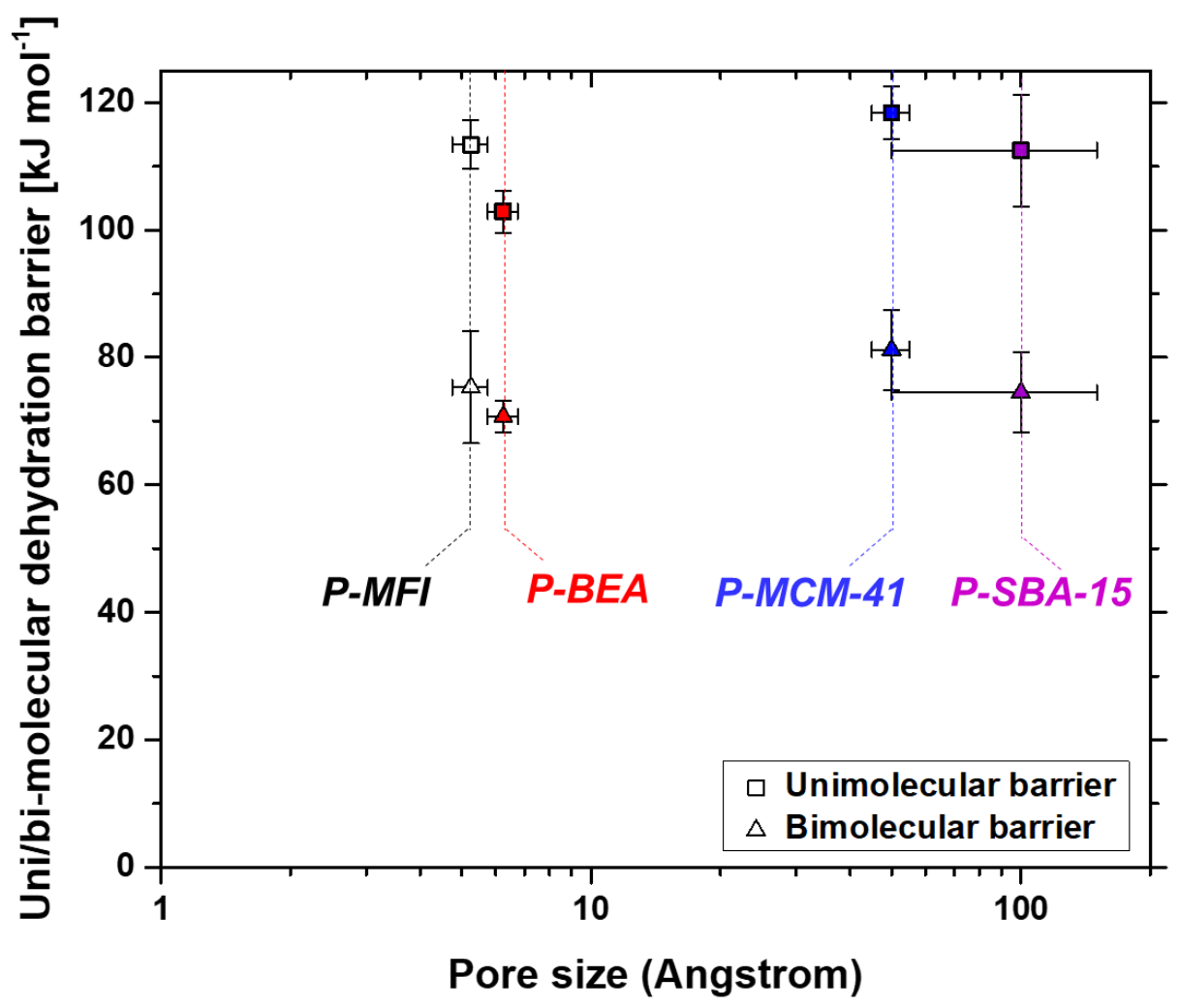

Figure S15. Apparent uni- and bimolecular dehydration barriers as a function of pore size for investigated P-zeosils. P-SPP is not included due to its hierarchical micro/mesoporous topology and lack of one representative pore size. 


\section{References}

(1) Zhang, X.; Liu, D.; Xu, D.; Asahina, S.; Cychosz, K. A.; Agrawal, K. V.; Al Wahedi, Y.; Bhan, A.; Al Hashimi, S.; Terasaki, O.; et al. Synthesis of Self-Pillared Zeolite Nanosheets by Repetitive Branching. Science 2012, 336 (6089), 1684-1687.

(2) Camblor, M. a.; Corma, A.; Valencia, S. Spontaneous nucleation and growth of pure silica zeoliteB free of connectivity defects. Chem. Commun. 1996, No. 20, 2365.

(3) Chézeau, J. M.; Delmotte, L.; Guth, J. L.; Soulard, M. High-resolution solid-state ${ }^{29}$ Si and ${ }^{13}$ C n.m.r. on highly siliceous MFI-type zeolites synthesized in nonalkaline fluoride medium. Zeolites 1989, 9 (1), 78-80.

(4) Zhao, D.; Feng, J.; Huo, Q.; Melosh, N.; Fredrickson, G. H.; Chmelka, B. F.; Stucky, G. D. Triblock Copolymer Syntheses of Mesoporous Silica with Periodic 50 to 300 Angstrom Pores. Science 1998, 279, 548-552.

(5) Werner Stober, A. F. Controlled Growth of Monodisperse Silica Spheres in the Micron Size Range. J. Phys. Ther. Sci. 2017, 29 (1), 112-114.

(6) Zhang, H. Fabrication of Zeolite MFI Membranes on Low Cost Polymer Supports. PhD thesis University of Minnesota 2017 (accessed 07/01/2021 from ProQuest: University of Minnesota Dissertations and theses database)

(7) Cho, H. J.; Ren, L.; Vattipalli, V.; Yeh, Y. H.; Gould, N.; Xu, B.; Gorte, R. J.; Lobo, R.; Dauenhauer, P. J.; Tsapatsis, M.; et al. Renewable p-Xylene from 2,5-Dimethylfuran and Ethylene Using Phosphorus-Containing Zeolite Catalysts. ChemCatChem 2017, 9 (3), 398-402.

(8) Chiang, H.; Bhan, A. Catalytic consequences of hydroxyl group location on the rate and mechanism of parallel dehydration reactions of ethanol over acidic zeolites. J. Catal. 2010, 271 (2), 251-261.

(9) Lin, Y.S., Ma, Y.H., A comparative study of adsorption and diffusion of vapor-alcohols and alcohols from aqueous solutions in silicalite. Stud. Surf. Sci. and Catal. 1989, 49, 877-866. 